\title{
ALCALÓIDES DE TABERNAEMONTANA \\ HETEROPHYLLA VAHL. (APOCYNACEAE) *
}

Wilson Wolter Filho **
Maria Lúcia Belém Pinheiro ***
Arnaldo Imbiriba da Rocha ***

\section{Resumo}

Dos extratos metanólicos da casca e do lenho da raíz da Tabernaemontana heterophylla Vahl. (Apocynaceae) foram isolados, além de sitosterol, lupeol e 3-O-acetil-lupeol, seis alcalóides indólicos: coronaridina, vobasina, affinisina, olivacina, voacangina e epiheyneanina.

\section{INTRODUC̣ĀO}

O estudo químico das espécies botânicas do gênero Tabernaemontana tem-se caracterizado pelo isolamento de alcalóides indólicos, principalmente, do tipo iboga, seguido por um número menor do tipo vobasina e affinisina (Patel et al., 1967; Matos et al., 1976 e Bruneton et al., 1980). Muitos desses alcalóides apresentam importantes propriedades farmacológicas (Kingston, 1978 e Gorman et al., 1960).

Meyer et al. (1973), ao estudarem as propriedades contraceptivas da coronaridina e da voacangina em ratas adultas, verificaram que a primeira inibe a fecundação, e que, nas mesmas condições, voacangina mostra-se inativa.
Kingston (1978) comprovou que voacangina possui atividade citotóxica em leucemia linfocítica $\mathrm{P}-388$. Essa atividade triplica-se na voacamina (produto da condensação da voacangina com a vobasina). E torna-se ainda mais pronunciada na epivoacorina, em que o monômero voacangina é hidroxilado em C-20.

\section{MATERIAL E MÉTODOS}

Os extratos metanólicos da casca e do lenho da raíz de T. heterophylla, coletada no Campus Universitário da Universidade Federal do Acre, foram submetidos, separadamente, ao tratamento esquematizado a seguir:

\section{1) CASCA DA RAIZ}

O extrato metanólico $(199,7 \mathrm{~g})$ da casca da raíz $(2.100 \mathrm{~g})$ forneceu $47,1 \mathrm{~g}$ de alcalóides totais. Deste, $18,0 \mathrm{~g}$ foram incorporados em sílica $(22,0 \mathrm{~g}$, Merck, art. 7734$)$, utilizando-se uma mistura de clorofórmio/metanol (7: 3). Após evapora-

\footnotetext{
* - Trabalho desenvolvido com apoio financeiro da SUBIN.

** - Instituto Nacional de Pesquisas da Amazônia - INPA/CNPq, Manaus.

** - Fundação Universidade do Amazonas - FUA, Manaus.
} 


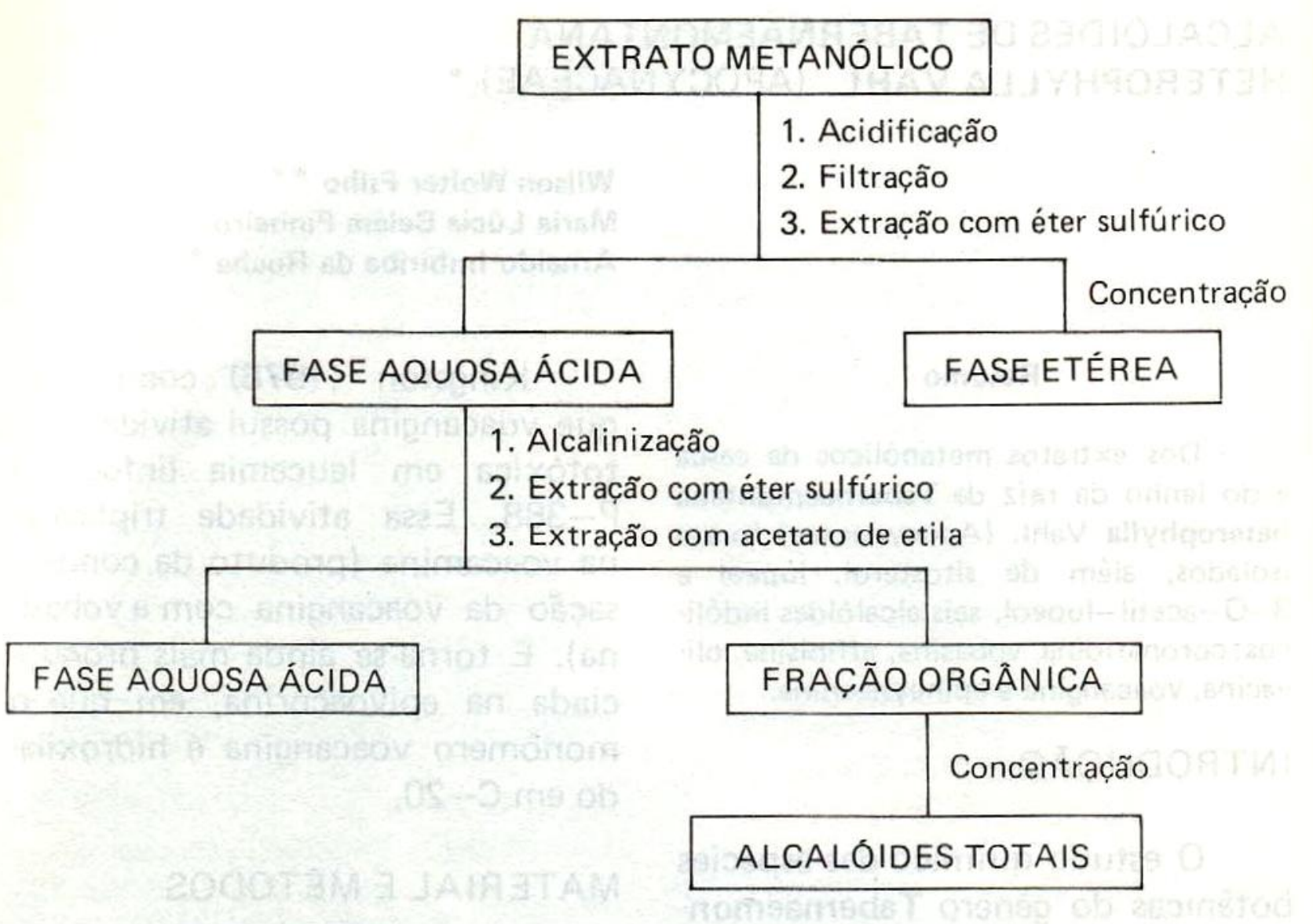

ção do solvente, o material disperso em sílica foi submetido à extração em aparelho tipo sohxlet, durante 12 horas, utilizando-se $n$-hexano como solvente.

A fração n-hexânica $(9,0 \mathrm{~g})$ permitiu isolar sem qualquer tratamento posterior, coronaridina $(7,20 \mathrm{~g})$, de cor escura e aspecto oleoso. Extração posterior com benzeno, benzeno/acetona, (9:1), acetato de etila e acetona, forneceram extratos individuais, respectivamente com os seguintes rendimentos: $1,2 \mathrm{~g}, 0,75 \mathrm{~g}, 1,6 \mathrm{~g}$ e $0,9 \mathrm{~g}$.

0 extrato benzênico $(1,2 \mathrm{~g})$ foi submetido à separação cromatográfica em coluna de sílica $(70,0$ g, Merck, art. 7734), usando-se benzeno e gradiente de benzeno/acetona como eluentes (frações de 25 $\mathrm{ml}$ ). As frações de 17 a 25 , eluídas como benzeno/acetona (8: 2), forneceram vobasina $(0,51 \mathrm{~g})$ (cristais incolores, p. f. 113,5-1160).

$\mathrm{O}$ extrato obtido com benzeno/acetona (9: 1) $(0,75 \mathrm{~g})$ foi submetido à separação cromatográfica em coluna de sílica $(50,0 \mathrm{~g}$, Merck, art. 7734), eluída com benzeno e benzeno/acetato de etila (9: 1, 8: 2 e $7,5: 2,5)$. As frações de 20 a 26 , eluídas com benzeno/acetato de etila $(7,5: 2,5)$, após evaporação do solvente, forneceram affinisina $(0,12 \mathrm{~g})$ (cristais incolores, $p . f$. 194-1970).

Os extratos obtidos com acetado de etila $(1,6 \mathrm{~g})$ e acetona $(0,9 \mathrm{~g})$ foram misturados e submetidos à separação cromatográfica em coluna de sílica $(170 \mathrm{~g}$, Merck, art. 
7734), eluída com benzeno, benzeno/acetona (9: 1, 8: $2,7: 3$ e $6: 4)$ e metanol. As frações de 14 a 28 eluídas com benzeno/acetona (6: 4) e 30 a 34 eluídas com metanol, após concentração dos solventes, forneceram olivacina $(1,05 \mathrm{~g})$ (cristais amarelos, p. f. 3150 com decomposição).

\section{2) LENHO DA RAIZ}

O extrato metanólico $(212 \mathrm{~g})$ do lenho da raíz $(4.300 \mathrm{~g})$ forneceu $26,10 \mathrm{~g}$ de alcalóides totais. Este, submetido às mesmas condições de fracionamento, que o extrato da casca da raíz, possibilitou além do isolamento de coronaridina e olivacina de duas outras substâncias, voacangina $(10,10 \mathrm{~g})$ (cristais incolores, p. f. 136-1370) e epiheyneanina $(1,10 \mathrm{~g})$ (cristais incolores, p. $f$. 170-1720), a partir de sua fração benzênica.

\section{RESULTADOS}

As substâncias foram identificadas por comparação dos dados espectrométricos e físicos com os registrados na literatura e com os de amostras autênticas para coronaridina (Raj et al., 1974); vobasina (Yamaguchi, 1970); affinisina (Cava et al., 1964); olivacina (Yamaguchi, 1970); voacangina (Raj et al., 1974) e epiheyneanina (Matos et al., 1976).

\section{DISCUSSÃO E CONCLUSĀO}

A ocorrência de teores significativos de coronaridina $140 \%$ dos alcalóides totais da casca da raíz) e voacangina $(39 \%$ dos alcalóides totais do lenho da raíz) em T. heterophylla, aliada às suas importantes propriedades biológicas, indicam a necessidade de estudo da distribuição da planta na região Amazônica, assim como de suas possibilidades de cultivo, visando à sua utilização como fonte natural de matéria prima para a indústria farmacêutica.

\section{SUMMARY}

Six indole alkaloids (coronaridine, voacangine, epiheyneanine, vobasine, affinisine and olivacine) as well as lupeol, 3-O-acetyllupeol and sitosterol were isolated from the roots of Tabernaemontana heterophylla Vahl.

BIBLIOGRAFIA

BRUNETON, J., CAVE, A.; MORETTI, C.

1979 - Study on two Species of Tabernaemontana in Guyana. Fitoterapia, 50(3) : 123.

CAVA, M.P., TALAPATRA, S.K., WEISBACH, J. A., DOUGLAS, B., RAFFAUF, R.F.; RIBEIRO, O.

1964 - Structures of Affinine and Affinisine, Alkaloids of Peschiera affinis (Muell. Arg.) Miers. Chem. and Ind., 26: 1193.

GORMAN, M., NEUS, N., CONE, N.J.; DEYRUP, J. A.

1960 - Alakaloids from Apocynaceae. III. Alkaloids of Tabernaemontana and Ervatamia. The structure of coronaridine. A new alkaloid related to ibogamine. J. Amer. Chem. Soc., 82 : 1142. 
KINGSTON, D. G. I.

1978 - Plant anticancer agents. VII: structural effects on cytotoxicity of bisindole alkaloids of voacamina type. J. Pharm. Sci., 67(2): 272.

1978 - Plant anticancer agents. VI: isolation of voacangine, voacamine and epivoacorine from Tabernaemontana arborea sp. J. Pharm. Sci., $67(2): 271$.

MATOS, F. J. A., BRAZ FILHO, R., GOTTILIEB, O. R., MACHADO, F. W.; MADRUGA, M. I. L.

1976 - 20-Epiheyneanina, an iboga alkaloid from Peschiera affinis. Phytochemistry, 15(4): 551.

MEYER, W. E., Coppola, J. A.; Goldman, L.

1973 - Alkaloid studies. VIII: isolation and characterization of alkaloids of Tabernaemontana heyneana Wall and antifertility properties of coronaridine. J. Pharm. Sci., 62(7): 1199.

PATEL, M. B., MIET, C.; POISSON, J.

1976 - Alcaloides de quelques Tabernaemontana africains. Ann. Pharm. Fr. 25(5) : 379.

RAJ, K., SHOEB, A., KAPIL, R. S.; POPLI, S. P.

1974 - Alkaloids of Tabernaemontana divaricata. Phytochemistry, 13(8): 1622.

YAMAGUCHI, $\mathrm{K}$.

1970 - Spectral Data of Natural Products. New York, American Elsevier Publishing Company Inc., Vol. 1.

(Aceito para publicação em $27 / 1 / 83$ ). 